\author{
Yoshihiro Sudo $\cdot$ Yoichi Ezura $\cdot$ Mitsuko Kajita \\ Hideyo Yoshida · Takao Suzuki · Takayuki Hosoi \\ Satoshi Inoue · Masataka Shiraki · Hiromoto Ito \\ Mitsuru Emi
}

\title{
Association of single nucleotide polymorphisms in the promoter region of the pro-opiomelanocortin gene (POMC) with low bone mineral density in adult women
}

Received: 10 December 2004 / Accepted: 23 February 2005/Published online: 29 April 2005

(C) The Japan Society of Human Genetics and Springer-Verlag 2005

\begin{abstract}
Among multiple factors influencing osteoporosis, genetic variations involved in bone-mineral metabolism can affect risks predisposing to the disease onset. Here, we studied single-nucleotide polymorphisms (SNPs) in the pro-opiomelanocortin (POMC) gene for possible association with bone mineral density
\end{abstract}

Y. Sudo $\cdot$ Y. Ezura $\cdot$ M. Kajita $\cdot$ M. Emi

Department of Molecular Biology,

Institute of Gerontology,

Nippon Medical School Kawasaki,

Kanagawa, Japan

Y. Sudo $\cdot$ H. Ito

Department of Orthopaedics,

Nippon Medical School,

Tokyo, Japan

H. Yoshida $\cdot$ T. Suzuki

Epidemiology and Health Promotion Research Group,

Tokyo Metropolitan Institute of Gerontology,

Tokyo, Japan

T. Hosoi

Department of Endocrinology,

Tokyo Metropolitan Geriatric Hospital,

Tokyo, Japan

S. Inoue

Department of Geriatric Medicine,

Faculty of Medicine,

University of Tokyo,

Tokyo, Japan

M. Shiraki

Research Institute and Practice for Involutional Diseases,

Nagano, Japan

Present address: Y. Ezura $(\square)$

Department of Molecular Pharmacology

Institute of Medical Research,

Tokyo Medical and Dental University,

2-3-10 Kanda-Surugadai,

Chiyoda-ku, Tokyo 101-0062, Japan

E-mail: ezura.mph@mri.tmd.ac.jp

Tel.: + 81-3-52808067

Fax: $+81-3-52808067$
(BMD) among 384 adult Japanese women and observed significant correlation between adjusted BMD and three SNPs in the promoter region $(r>0.14, p<0.01)$. The most significant correlation was observed for $-2353 \mathrm{G} / \mathrm{A}$ $(r=-0.16, p=0.002)$; homozygous carriers of the major (G) allele had the highest BMD $\left(0.405 \pm 0.054 \mathrm{~g} / \mathrm{cm}^{2}\right)$ while heterozygous carriers were intermediate $\left(0.390 \pm 0.053 \mathrm{~g} / \mathrm{cm}^{2}\right)$ and homozygous A-allele carriers had the lowest BMDs $\left(0.369 \pm 0.048 \mathrm{~g} / \mathrm{cm}^{2}\right)$. Although no association was detected between these SNPs and body weight or body mass index (BMI), significant association was detected between the $-2313 \mathrm{~A} / \mathrm{C}$ genotype and plasma total cholesterol level $(r=-0.12$, $p=0.019$ ). We propose that $P O M C$ is among the likely susceptibility genes for osteoporosis and may also be involved in dyslipidemia.

Keywords Single nucleotide polymorphism .

Pro-opiomelanocortin (POMC) - Bone mineral density · Association study $\cdot$ Osteoporosis

\section{Introduction}

Osteoporosis, one of the most prevalent disease conditions in older age groups, is pathologically defined by low bone mineral density (BMD) and deterioration of bone structure (Riggs and Melton 1986; Kanis et al. 1994). Like many other common diseases, multiple factors, including genetic variations, determine predisposition for onset or progression of osteoporosis, as has been indicated by genetic-epidemiological studies (Peacock et al. 2002; Albagha and Ralston 2003). Numerous studies on genetic risks for osteoporosis have been investigated to date, mainly by association studies and linkage analysis for quantitative trait BMD (Liu et al. 2003).

Among those studies, a quantitative trait locus (QTL) for spinal BMD has been identified in the chromosomal region 2p23-24 in large Caucasian pedigrees (Devote 
et al. 1998). An independent study for distal forearm BMD in Chinese (Niu et al. 1999) detected contribution of similar locus (2p23.3) expanding about 18-Mbp, which completely overlaps the formerly detected locus (about 5-Mbp; markers from D2S149 to D2S387). In the later study, several candidates, including the pro-opiomelanocortin gene (POMC), were proposed; however, no responsible variations have been identified as yet.

An important aspect of BMD regulation is conducted through immunological responses to inflammatory events, presumably through activation of osteoclastogenesis (Manolagas 1995; Rodan and Martin 2000). In addition to complex cytokine pathways for which the most attention have been paid, regulation through endocrine systems, notably hormonal regulation of adrenal corticoids, is important, as indicated by clinical knowledge of glucocorticoid-induced osteoporosis (Patschan et al. 2001). Moreover, higher hierarchical regulation of systemic corticoid levels, i.e., hypothalamus-pituitary-adrenal axis (HPA-axis), may have critical effects on homeostatic regulation of the immune system. Thus, genes involved in this system, such as $P O M C$, should be considered for the association study.

POMC is a large precursor protein for multiple functional peptide hormones, including adrenocorticotrophic hormone (ACTH), melanocyte-stimulating hormones (alpha-MSH, beta-MSH, and gamma-MSH), and beta-endorphin. In addition to classical knowledge of influences on serum corticoid levels or on metabolic control of energy expenditure and body mass (Pritchard et al. 2002; Appleyard et al. 2003), direct and indirect effects of these peptides on the immune system have been clarified recently (Luger et al. 2003). Here, in this study, we investigated the eight single nucleotide polymorphisms (SNPs) of the POMC as good candidates for testing association between the genotypes and bone phenotype. In addition, to evaluate the effects on other metabolic systems, we investigated the association of body mass index (BMI) and serum cholesterol levels to the genotypes among 384 adult Japanese women.

\section{Materials and methods}

Subjects

DNA samples were obtained from peripheral blood of 384 adult Japanese women (Ishida et al. 2003; Iwasaki et al. 2003). All were nonrelated volunteers who gave informed consent prior to the study. No participant had medical complications or was undergoing treatment for conditions known to affect bone and lipid metabolism, such as pituitary diseases, hyperthyroidism, primary hyperparathyroidism, liver disease, renal failure, adrenal diseases, or rheumatic diseases, and none was receiving estrogen replacement therapy. Physical and clinical profiles of the subjects, including age, body weight, height, BMD, plasma total cholesterol (T-chol), triglycerides, and high-density lipoprotein cholesterol (HDLC) levels were obtained from the records of a healthcheck screening program. Mean values and standard deviations (SD) were $58.4 \pm 8.6$ (range 32-69) years for age, and $23.7 \pm 3.61 \mathrm{~kg} / \mathrm{m}^{2}$ (range 14.7-38.5) for BMI. The areal BMD (expressed in grams per centimeter squared) of the distal radius, measured by dual energy X-ray absorptiometry (DXA) using DTX-200 (Osteometer Meditech Inc., Hawthorne, CA, USA) showed normal distribution $\left(0.399 \pm 0.054 \mathrm{~g} / \mathrm{cm}^{2}\right.$; range 0.225 0.554). Among 384 subjects, we regarded 64 individuals as low-bone-mass subjects whose adjusted BMD distributed below 0.38 (mean adjusted BMD-1SD) and 55 individuals as high-bone-mass subjects whose adjusted BMD was above 0.48 (mean adjusted BMD + 1SD). Plasma lipid and lipoprotein concentrations were measured from peripheral blood collected after $12-16 \mathrm{~h}$ of fasting by procedures described previously (Hattori et al. 2002). All measured values were within the normal range (T-chol: $187.0 \pm 32.2 \mathrm{mg} / \mathrm{dl}$, triglycerides: $85.5 \pm 59.8 \mathrm{mg} / \mathrm{dl}, \mathrm{HDL}-\mathrm{C}: 59.1 \pm 12.2 \mathrm{mg} / \mathrm{dl})$.

Genotyping for molecular variants in the POMC gene

Eight SNPs (Table 1) from the NCBI database (dbSNP) or the Celera database (Celera Diagnostics, Rockville, MD, USA) were selected and denoted as $-2353 \mathrm{G} / \mathrm{A}$, $-2345 \mathrm{G} / \mathrm{A}, \quad-2313 \mathrm{~A} / \mathrm{C}, \quad-1845 \mathrm{C} / \mathrm{T}, \quad \mathrm{IVS} 1+267 \mathrm{C} / \mathrm{G}$, IVS2 $+276 \mathrm{C} / \mathrm{G}, \mathrm{A} 132 \mathrm{P}$ (c.396G/C), and c.585T/C (195Ala) according to their positions in a contig-sequence (NT_022184.13; NCBI RefSeq database) (Fig. 1a). All were confirmed to be polymorphic in our test population $(n=24)$, and thus, the 384 subjects were genotyped either by cycle sequencing, TaqMan Assay (Livak 1999), or Invader assay (Mein et al. 2000) (Table 1).

For five SNPs $(-2353 \mathrm{G} / \mathrm{A},-2313 \mathrm{~A} / \mathrm{C},-2345 \mathrm{G} / \mathrm{A}$, $-1845 \mathrm{C} / \mathrm{T}$, and $\mathrm{A} 132 \mathrm{P})$, cycle sequencing was carried
Table 1 Summary of polymorphisms examined at the POMC locus

\footnotetext{
${ }^{\text {a }}$ Location of the SNP was defined by NT_023195.12 from the NCBI RefSeq database b Identity number for NCBI dbSNP database

c Identity number for Celera database
}

\begin{tabular}{lllll}
\hline SNP name $^{\mathrm{a}}$ & dbSNP-ID $^{\mathrm{b}}$ & Celera-ID $^{\mathrm{c}}$ & Allele frequency & \% heterozygosity \\
\hline$-2353 \mathrm{G} / \mathrm{A}$ & $\mathrm{rs} 3754863$ & & $0.81: 0.19$ & 32 \\
$-2345 \mathrm{G} / \mathrm{A}$ & $\mathrm{rs} 3754862$ & & $0.81: 0.19$ & 32 \\
$-2313 \mathrm{~A} / \mathrm{C}$ & $\mathrm{rs} 3754861$ & & $0.79: 0.21$ & 28 \\
$-1845 \mathrm{C} / \mathrm{T}$ & $\mathrm{rs} 3754860$ & & $0.74: 0.26$ & 38 \\
$\mathrm{IVS} 1+267 \mathrm{C} / \mathrm{G}$ & $\mathrm{rs} 1009388$ & & $0.98: 0.02$ & 5 \\
$\mathrm{IVS} 2+276 \mathrm{C} / \mathrm{G}$ & - & hCV3227244 & $0.68: 0.32$ & 39 \\
A132P & rs8192606 & & $0.99: 0.01$ & 1 \\
c.585T/G & rs2071345 & & $0.72: 0.28$ & 40 \\
\hline
\end{tabular}


Fig. 1 Analysis of the linkage disequilibrium within the $P O M C$ locus. a Schematic diagram of the $P O M C$ gene showing positions of the eight examined SNPs. b Indices of $\mathrm{LD}, D^{\prime}$ and $r^{2}$ were calculated on the basis of 17 estimated haplotypes (covering 100\% of the chromosomes) constructed with six SNPs. Cells are highlighted with gray halftone when the $D^{\prime}$ values are greater than 0.4 or the $r^{2}$ values are greater than 0.1
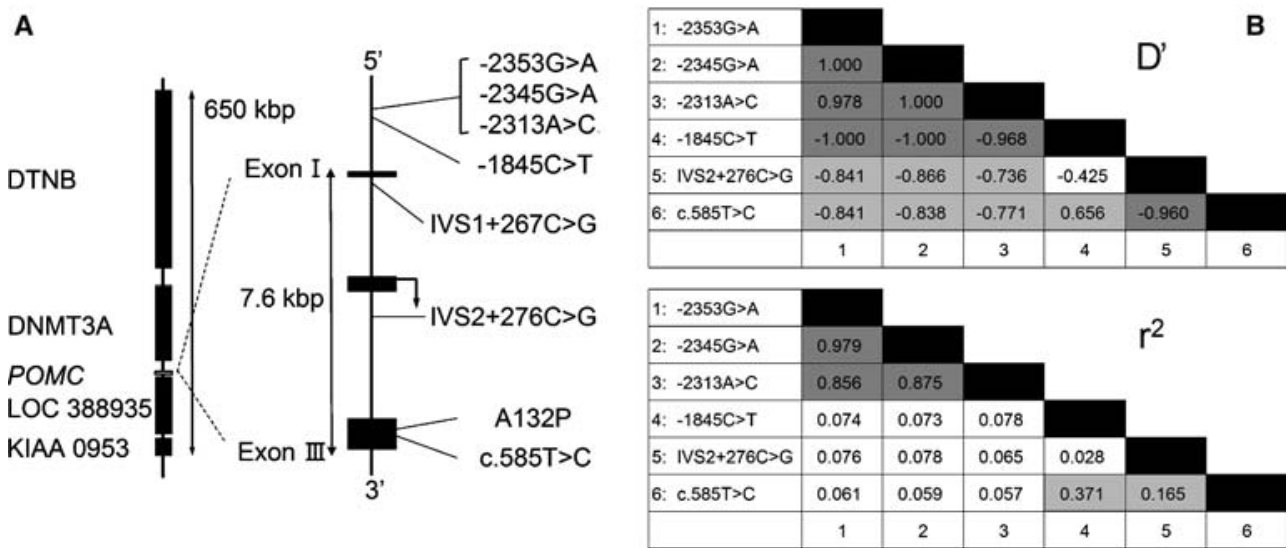

out using the BigDye terminator v1.1 Cycle Sequencing Kit (Applied Biosystems, Foster City, CA, USA) and the ABI PRISM 377 DNA Sequencing System (Applied Biosystems). The following primers were used: F-1, 5'ACTCTTTCAAGCAGATGGTGGT-3' and R-1, 5'AGCAGGTTCTGCTGCATTAAA-3' (for SNP $-1845 \mathrm{C} / \mathrm{T}) ; \mathrm{F}-2, \quad 5^{\prime}$-AAGGCCATTGAACTGCATTTAG-3' and R-2, 5'-GTCTATGTCAGACGCCTGTGGT-3' (for $-2353 \mathrm{G} / \mathrm{A},-2313 \mathrm{~A} / \mathrm{C}$ and $-2345 \mathrm{G} / \mathrm{A}$ ); and $\mathrm{F}-3,5^{\prime}$-AACCCCCGGAAGTACGTCAT- $3^{\prime}$ and R-3, 5'-GAAGTGCTCCATCCTGTAGGG-3' (for A132P). TaqMan assay was carried out for IVS $2+4229 \mathrm{C} / \mathrm{G}$ and c. $585 \mathrm{~T} / \mathrm{C}$, according to the manufacturers' protocol (TaqMan Assays-on-Demand; Applied Biosystems). Invader assay was carried out for IVS1 $+352 \mathrm{C} / \mathrm{G}$ according to the manufacturers' protocol (Invader Assay: Third Wave Technologies, inc, Madison City, WI, USA) and the methods described previously (Ezura et al. 2003).

\section{Statistical analysis}

Adjusted values of BMD were obtained after normalizing the measured data with age and BMI by means of multiple regression analysis, as described previously (Iwasaki et al. 2003). Plasma lipids and lipoprotein concentrations were adjusted by reference to an age group (40-49 years) among standard data from 11,994 individuals in a 2001 cohort study for the Japanese population, using a $Z$-score calculation (Fujita et al. 2003).

The three genotypic categories of each SNP were converted into incremental values 0,1 , and 2 , corresponding to the number of chromosomes possessing a minor allele, and quantitative association with several physical and clinical values was analyzed via one-way analysis of variance (ANOVA) with linear regression analysis as a post hoc test. The statistical significance of any correlation was accepted when the given $p$ values of the ANOVA $F$ test were less than $5 \%(p<0.05)$. To test the existence of dominant or recessive effects of minor allele of each SNP, Student's $t$ test was applied to compare two divided subject groups by possession of minor allele or major allele $(p<0.05)$. Distribution analysis of contingency tables were applied for lowbone-mass $(n=64)$ or high-bone-mass individuals $(n=55)$. Chi-square test for trend was applied $(p<0.05)$. Hardy-Weinberg equilibrium among genotypes was ascertained by the chi-square test. A maximum-likelihood haplotype was estimated by the EM algorithm using Arlequin software (Genetics and Biometry Laboratory, Geneva, Switzerland) (Schneider et al. 2000), and indices of linkage disequilibrium (LD) were calculated.

\section{Results}

Eight SNPs in the POMC gene, one of the likely candidates for osteoporosis susceptibility, were examined in all 384 subjects. Allelic frequencies and genotypic frequencies were clarified and showed no deviation from Hardy-Weinberg equilibrium (Table 1). By excluding the data from two rare SNPs (IVS1 $+352 \mathrm{C} / \mathrm{G}$ and A132P), we estimated haplotype frequencies from available genotypic data for the other six SNPs. The LD analysis, evaluated by $D^{\prime}$ and $r^{2}$ for every combination of SNPs, indicated apparent LD within the locus (Fig. 1b). Especially strong LD was detected among $-2353 \mathrm{G} / \mathrm{A},-2345 \mathrm{G} / \mathrm{A}$, and $-2313 \mathrm{~A} / \mathrm{C}\left(D^{\prime}>0.97, r^{2}\right.$ $>0.85$ ).

By examining a correlation between SNP genotype and adjusted BMD for each of the eight SNPs (Table 2), significant correlation was evident with three promoter SNPs $(-2353 \mathrm{G} / \mathrm{A},-2345 \mathrm{G} / \mathrm{A}$, and $-2313 \mathrm{~A} / \mathrm{C})$. For the most significant $-2353 \mathrm{G} / \mathrm{A} \quad(r=-0.16, \quad p=0.0020)$, codominant BMD lowering effect of the minor A-allele was indicated where homozygous carriers of G-alleles had the highest values $\left(0.405 \pm 0.054 \mathrm{~g} / \mathrm{cm}^{2}\right)$, heterozygous individuals were intermediate $(0.390 \pm 0.053 \mathrm{~g} /$ $\mathrm{cm}^{2}$ ), and homozygous A-allele carriers had the lowest adjusted BMDs $\left(0.369 \pm 0.048 \mathrm{~g} / \mathrm{cm}^{2}\right)$ (Fig. 2a). Dominant or codominant effect was supported by analyzing the differences between two genotypically divided groups based on dominant model (A-allele carriers: $n=132, \quad$ adj-BMD $=0.388 \pm 0.053$; and noncarriers: $n=242$, adj-BMD $=0.405 \pm 0.054, p=0.004$, Student's $t$ test) and recessive model (G-allele carriers: $n=365$, $\operatorname{adj-BMD}=0.400 \pm 0.054 ; \quad$ and noncarriers: $n=9$, 
Table 2 Summary of the regression analysis of $P O M C$ variations among 384 subjects. BMD bone mineral density

\begin{tabular}{|c|c|c|c|c|c|c|}
\hline SNP name & Number $^{\mathrm{a}}$ & Major homo $(n)$ & Hetero $(n)$ & Minor homo $(n)$ & Correlation coefficient & $p$ value \\
\hline & & \multicolumn{5}{|c|}{ Adjusted BMD $\left(\mathrm{g} / \mathrm{cm}^{2}\right)$} \\
\hline$-2353 \mathrm{G} / \mathrm{A}$ & 374 & $0.405 \pm 0.054(242)$ & $0.390 \pm 0.053$ & $0.369 \pm 0.048$ & -0.16 & 0.002 \\
\hline$-2345 \mathrm{G} / \mathrm{A}$ & 374 & $0.404 \pm 0.055$ & $0.391 \pm 0.052(121)$ & $0.369 \pm 0.048(9)$ & -0.14 & 0.005 \\
\hline$-2313 \mathrm{~A} / \mathrm{C}$ & 374 & $0.404 \pm 0.055$ & $0.392 \pm 0.052(106)$ & $0.376 \pm 0.051$ & -0.15 & 0.004 \\
\hline$-1845 \mathrm{C} / \mathrm{T}$ & 375 & $0.397 \pm 0.052(206)$ & $0.402 \pm 0.057$ & $0.403 \pm 0.055(26)$ & 0.05 & 0.35 \\
\hline $\mathrm{IVS} 1+267 \mathrm{C} / \mathrm{G}$ & 329 & $0.401 \pm 0.056(314)$ & $0.376 \pm 0.050$ & $(-)$ & 0.09 & 0.09 \\
\hline $\mathrm{IVS} 2+276 \mathrm{C} / \mathrm{G}$ & 376 & $0.401 \pm 0.057(184)$ & $0.398 \pm 0.051(145)$ & $0.401 \pm 0.056(47)$ & -0.02 & 0.76 \\
\hline A132P & 373 & $0.399 \pm 0.055(367)$ & $0.425 \pm 0.038$ & $(-)$ & 0.05 & 0.35 \\
\hline \multirow[t]{2}{*}{ c. $585 \mathrm{~T} / \mathrm{G}$} & 377 & $0.397 \pm 0.054(195)$ & $0.401 \pm 0.054(151)$ & $0.409 \pm 0.063$ & 0.06 & 0.28 \\
\hline & & \multicolumn{5}{|c|}{ Adjusted total cholesterol $(\mathrm{mg} / \mathrm{dl})$} \\
\hline$-2353 \mathrm{G} / \mathrm{A}$ & 374 & $189.4 \pm 34.0(242)$ & $183.2 \pm 27.9(123)$ & $174.9 \pm 16.7(9)$ & -0.11 & 0.036 \\
\hline$-2345 \mathrm{G} / \mathrm{A}$ & 374 & $189.6 \pm 34.0(244)$ & $182.7 \pm 27.8(121)$ & $174.9 \pm 16.7(9)$ & -0.12 & 0.024 \\
\hline$-2313 \mathrm{~A} / \mathrm{C}$ & 374 & $189.6 \pm 34.0(244)$ & $183.4 \pm 27.1(106)$ & $176.7 \pm 27.3(24)$ & -0.12 & 0.019 \\
\hline$-1845 \mathrm{C} / \mathrm{T}$ & 375 & $186.9 \pm 32.1(206)$ & $186.2 \pm 29.8(143)$ & $195.1 \pm 42.7(26)$ & 0.04 & 0.479 \\
\hline $\mathrm{IVS} 1+267 \mathrm{C} / \mathrm{G}$ & 329 & $187.3 \pm 32.0(314)$ & $185.7 \pm 27.1(15)$ & $(-)$ & -0.01 & 0.848 \\
\hline $\mathrm{IVS} 2+276 \mathrm{C} / \mathrm{G}$ & 376 & $185.0 \pm 29.7(184)$ & $185.1 \pm 32.9(145)$ & $195.8 \pm 32.2(47)$ & 0.08 & 0.100 \\
\hline A132P & 373 & $186.8 \pm 32.2(367)$ & $192.3 \pm 58.1$ & $(-)$ & 0.02 & 0.737 \\
\hline c. $585 \mathrm{~T} / \mathrm{G}$ & 377 & $186.0 \pm 30.2(195)$ & $187.3 \pm 33.4(151)$ & $187.8 \pm 35.3(31)$ & 0.02 & 0.683 \\
\hline
\end{tabular}

a represents the number of genotyped subjects

${ }^{\mathrm{b}} p$ values are calculated for the regression analysis with ANOVA $F$ test

adj-BMD $=0.369 \pm 0.048, p=0.09$, Student's $t$ test). The other two promoter SNPs also demonstrated allelicdosage effects (data not shown). By comparing the distribution of genotypically divided subjects among lowbone-mass individuals $(n=64 ; 36,25$, and three individuals for $\mathrm{G} / \mathrm{G}, \mathrm{A} / \mathrm{G}$, and $\mathrm{A} / \mathrm{A}$ genotypes, respectively) and high-bone-mass individuals $(n=55 ; 43$ and 12 individuals for $\mathrm{G} / \mathrm{G}$ and $\mathrm{A} / \mathrm{G}$ : no individual for $\mathrm{A} / \mathrm{A}$ ), significant difference with trend was detected $(p=0.006)$, indicating minor A-allele of $-2353 \mathrm{G} / \mathrm{A}$ could be a genetic risk for low-bone-mass trait.

We examined whether these variations correlated with other clinical features (Table 2). The same three promoter SNPs $(-2353 \mathrm{G} / \mathrm{A},-2345 \mathrm{G} / \mathrm{A}$, and $-2313 \mathrm{~A} /$ C) demonstrated significant correlation to adjusted T-chol levels (ex; $-2313 \mathrm{~A} / \mathrm{C} ; \quad r=-0.12, \quad p=0.019$ ) (Fig. 2b). No significant correlations were detected

Fig. 2 Effects of $P O M C$ variations on adjusted bone mineral density (BMD) and total cholesterol (T-chol) in plasma. Adjusted BMD levels were plotted against three genotypically classified subgroups at the $-2353 \mathrm{G} / \mathrm{A}$ SNP site. Adjusted T-chol levels were plotted against genotypically classified subgroups at $-2313 \mathrm{~A} / \mathrm{C}$ site. The allelic-dosage effects of these variants on BMD or T-chol were analyzed by linear regression as a post-hoc test of ANOVA. Calculations of $p$ values were based on $F$ tests. Open circles indicate mean values, error bars indicate standard deviations

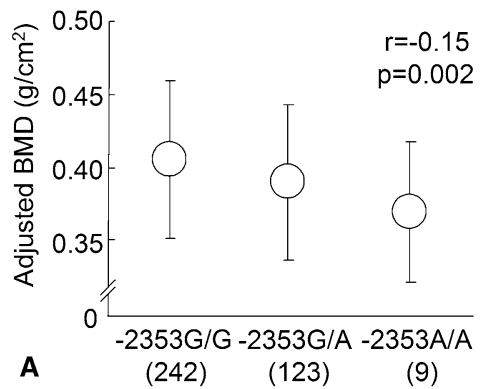

between other covariates (age, body weight, height, BMI or adjusted plasma HDL-C and triglyceride levels) and any SNPs.

\section{Discussion}

In the work reported here, we detected significant association between genotypes of three POMC variations $(-2353 \mathrm{G} / \mathrm{A},-2345 \mathrm{G} / \mathrm{A}$, and $-2313 \mathrm{~A} / \mathrm{C})$ and adjusted levels of radial BMD among adult Japanese women. In addition, the same promoter SNPs showed an association with plasma T-chol level but not with body mass. These data indicated possible influences of POMC polymorphism(s) on bone-mineral status for the first time, as well as on lipoprotein metabolism.

Association of promoter SNP genotype to low-bonemass phenotype indicates that the altered level of POMC peptide might affect the bone metabolism. Lowered BMD can result from accelerated bone loss and/or deficient acquisition of bone mass (Riggs and Melton 1986). However, because bone loss caused by systemic corticoid use is thought to occur mainly through resorption (Weinstein et al. 2002, 2004), POMC variations would also affect resorptive mechanisms. In addition, anabolic aspect of corticoid function should be

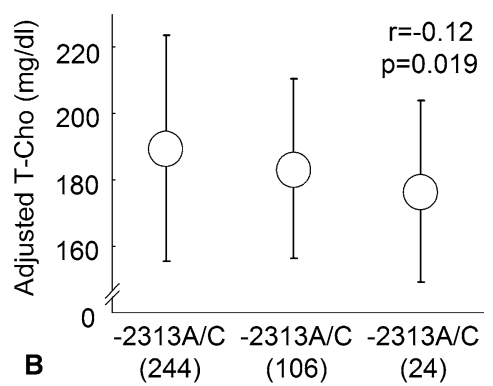


considered on the skeletal system through multiple pathways (Patschan et al. 2001). In the feedback system of HPA-axis, multiple cross-talks between the corticotropin releasing hormone, somatostatin growth hormone system, gonadotropin system, and thyroid hormone are known. Longitudinal studies in large cohorts, as well as functional studies, may clarify the molecular events by which SNPs in the POMC promoter bring about alterations in bone metabolism. Presumably, these variation(s) affect transcription of the ACTH-precursor peptide, which should affect secretion of ACTH from the anterior pituitary and/or the regulation of other POMC-derived peptide hormones. The consequent effects on bone metabolism might, in turn, introduce variation in BMD in an adult woman. Those assumptions should be validated by additional studies.

As mentioned, $P O M C$ was selected as a candidate because it is a precursor of ACTH. Although its function on the skeletal system may mainly depend on the catabolic aspect of corticoids, alternative pathways would also contribute, as described. In addition, other POMCderived peptides, such as MSHs, could be responsible for alterations in bone metabolism. Anti-inflammatory function of alpha-MSH through effects on macrophages has been reported (Star et al. 1995). Also, alpha-MSH and beta-endorphin functioning in body-mass maintenance and in energy expenditure may contribute to bone-mass regulation because a close relationship between these two regulatory systems has been assumed (Reid 2002).

Interrelationship between these clinical phenotypes has been documented: Individuals carrying $P O M C$ mutations that impair synthesis of ACTH and alphaMSH were reported to become obese (Krude et al. 1998). In addition, linkage and association of the POMC locus were reported for the serum leptin level (Hixson et al. 1999), fasting insulin level (Santoro et al. 2004), and obesity (Delplanque et al. 2000). However, in our test subjects, we detected no significant correlation between the SNP genotype and the indices of obesity; thus, the correlation we observed between BMD and the SNP genotypes was not secondary to altered body mass. Instead, we found an association between variant $-2313 \mathrm{~A} / \mathrm{C}$ and adjusted T-chol. Although the detected correlation was weak and reproducibility of this finding or the correlation between the low-density lipoprotein cholesterol (LDL-C) and the genotype was no investigated in our study, the possibility has to be examined in a future study as to whether POMC-derived peptides regulate lipoprotein metabolism through a distinctive mechanism.

Another of our findings, the existence of strong LD among the three significantly BMD-correlated promoter SNPs, may imply an important promoter/enhancer function of the region they share up-stream of the $P O M C$ coding sequence. In fact, a computer algorithm, MatInspector program v2.2 (Quandt et al. 1995), predicted that two of these three SNPs were part of presumed consensus binding sequences of known tran- scription factors; i.e., $-2345 \mathrm{G} / \mathrm{A}$ in the acute myeloid leukemia (AML) - la binding sequence (TGCGGT; underlined " $\mathrm{G}$ " is a variant nucleotide) and $-235 \overline{\mathrm{G}} / \mathrm{A}$ in the GATA-1 or GATA-2 sequence (CGAGATCGCG; underlined " $G$ " is a variant nucleotide). The functional significance of these cis elements and trans factors remains to be clarified. Of course, our study does not stipulate specific $\operatorname{SNP}(s)$ that functionally regulate BMD. Thus, we cannot rule out the possibility that these polymorphic markers at chromosome 2 (2p23) may themselves be in linkage disequilibrium with other, unmeasured functional variants (see Fig. 1). Functional studies as well as longitudinal studies will be required to find a true mechanistic basis for the associations reported here.

In summary, we have shown a significant association of three variations in the promoter region of the $P O M C$ gene $(-2353 \mathrm{G} / \mathrm{A},-2345 \mathrm{G} / \mathrm{A}$, and $-2313 \mathrm{~A} / \mathrm{C})$ with radial BMD levels among adult Japanese women. An association was also detected between these SNPs and plasma cholesterol levels. Structural inspection proposed that transcription factors AML-1a and GATA-1 or -2 might bind to sequences containing these SNP sites. Detailed investigations involving molecules of the HPA axis may clarify the true mechanism of $\mathrm{BMD}$ regulation by $P O M C$ SNPs.

Acknowledgements We thank Mina Kodaira, Miho Kawagoe, and Naoko Tsuruta for their expert technical assistance. This work was supported by a grant for Strategic Research from the Ministry of Education, Science, Sports and Culture of Japan; by a Research Grant for Research from the Ministry of Health and Welfare of Japan; and by a Research for the Future Program Grant of The Japan Society for the Promotion of Science.

\section{References}

Albagha OM, Ralston SH (2003) Genetic determinants of susceptibility to osteoporosis. Endocrinol Metab Clin North Am 32:65-81

Appleyard SM, Hayward M, Young JI, Butler AA, Cone RD, Rubinstein M, Low MJ (2003) A role for the endogenous opioid beta-endorphin in energy homeostasis. Endocrinology 144:1753-1760

Delplanque J, Barat-Houari M, Dina C, Gallina P, Clement K, Guy-Grand B, Vasseur F, Boutin P, Froguel P (2000) Linkage and association studies between the proopiomelanocortin (POMC) gene and obesity in caucasian families. Diabetologia 43:1554-1557

Devote M, Shimoya K, Caminis J, Ott J, Tenenhouse A, Whyte MP, Sereda L, Hall S, Considine E, Williams CJ, Tromp G, Kuivaniemi H, Ala-Kokko L, Proskop DJ, Spotila LD (1998) First-stage autosomal genome screen in extended pedigrees suggests genes predisposing to low bone mineral density on chromosomes 1p, 2p and 4p. Eur J Hum Genet 6:151-157

Ezura Y, Kajita M, Ishida R, Yoshida S, Yoshida H, Suzuki T, Hosoi T, Inoue S, Shiraki M, Orimo H, Emi M (2003) Association of multiple nucleotide variations in the pituitary glutaminyl cyclase gene (QPCT) with low radial BMD in adult women. J Bone Miner Res 19:1296-1301

Fujita Y, Ezura Y, Emi M, Sato K, Takada D, Iino Y, Katayama Y, Takahashi K, Kamimura K, Bujo H, Saito Y (2003) Hypercholesterolemia associated with splice-junction variation of inter-alpha-trypsin inhibitor heavy chain 4 (ITIH4) gene. J Hum Genet 49:24-28 
Hattori H, Hirayama T, Nobe Y, Nagano M, Kujiraoka T, Egashira T, Ishii J, Thuji M, Emi M (2002) Eight novel mutations and functional impairments of the LDL receptor. $\mathrm{J}$ Hum Genet 47:80-87

Hixson JE, Almasy L, Cole S, Birnbaum S, Mitchell BD, Mahaney MC, Stern MP, MacCluer JW, Blangero J, Comuzzie AG (1999) Normal variation in leptin levels is associated with polymorphisms in the proopiomelanocortin gene, POMC. J Clin Endocrinol Metab 84:3187-3191

Ishida R, Ezura Y, Emi M, Kajita M, Yoshida H, Suzuki T, Hosoi T, Inoue S, Shiraki M, Ito H, Orimo H (2003) Association of a promoter haplotype $(-1542 \mathrm{G} /-525 \mathrm{C})$ in the tumor necrosis factor receptor associated factor-interacting protein gene with low bone mineral density in Japanese women. Bone 33:237-241

Iwasaki H, Emi M, Ezura Y, Ishida R, Suzuki T, Hosoi T, Inoue S, Shiraki M, Swensen J, Orimo H (2003) Association of a Trp16Ser variation in the gonadotropin releasing hormone signal peptide with bone mineral density, revealed by SNPdependent PCR typing. Bone 32:185-190

Kanis JA, Melton LJ, Christiansen C, Johnston CC, Khaltaev N (1994) The diagnosis of osteoporosis. J Bone Miner Res 9:11371141

Krude H, Biebermann H, Luck W, Horn R, Brabant G, Gruters A (1998) Severe early-onset obesity, adrenal insufficiency and red hair pigmentation caused by POMC mutations in humans. Nat Genet 19:155-157

Liu YZ, Liu YJ, Robert RR, Deng HW (2003) Molecular studies of identification of genes for osteoporosis: the 2002 update. Endocrinology 177:147-196

Livak KJ (1999) Allelic discrimination using fluorogenic probes and the $5^{\prime}$ nuclease assay. Genet Anal 14:143-149

Luger TA, Scholzen TE, Brzoska T, Bohm M (2003) New insights into the functions of alpha-MSH and related peptides in the immune system. Ann NY Acad Sci 994:133-140

Manolagas SC (1995) Role of cytokines in bone resorption. Bone 17:63-67

Mein CA, Barratt BJ, Dunn MG, Siegmund T, Smith AN, Esposito L, Nutland S, Stevens HE, Wilson AJ, Phillips MS, Jarvis N, Law S, de Arruda M, Todd JA (2000) Evaluation of single nucleotide polymorphism typing with invader on PCR amplicons and its automation. Genome Res 10:330-343
Niu T, Chen C, Cordell H, Yang J, Wang B, Wang Z, Fang Z, Nicholas JS, Clifford JR, Xu X (1999) A genome-wide scan for loci linked to forearm bone mineral density. Hum Genet 104:226-233

Patschan D, Loddenkemper K, Buttgereit F (2001) Molecular mechanisms of glucocorticoid-induced osteoporosis. Bone 29:498-505

Peacock M, Turner CH, Econs MJ, Foroud T (2002) Genetics of osteoporosis. Endocrinol Rev 23:303-326

Pritchard LE, Turnbull AV, White A (2002) Pro-opiomelanocortin processing in the hypothalamus: impact on melanocortin signaling and obesity. J Endocrinol 172:411-421

Quandt K, Frech K, Karas H, Wingender E, Werner T (1995) MatInd and MatInspector: new fast and versatile tools for detection of consensus matches in nucleotide sequence data. Nucleic Acids Res 23:4878-4884

Reid IR (2002) Relationships among body mass, its components, and bone. Bone 31:547-555

Riggs BL, Melton LJ III (1986) Involutional osteoporosis. N Engl J Med 314:1676-1686

Rodan GA, Martin TJ (2000) Therapeutic approaches to bone diseases. Science 289:1508-1514

Santoro N, del Giudice EM, Cirillo G, Raimondo P, Corsi I, Amato A, Grandone A, Perrone L (2004) An insertional polymorphism of the proopiomelanocortin gene is associated with fasting insulin levels in childhood obesity. J Clin Endocrinol Metab 89:4846-4849

Schneider S, Roessli D, Excoffier L (2000) Arlequin ver. 2.000: a software for population genetics data analysis. Genetics and Biometry Laboratory, University of Geneva, Geneva, Switzerland

Star RA, Rajora N, Huang J, Stock RC, Catania A, Lipton JM (1995) Evidence of autocrine modulation of macrophage nitric oxide synthase by alpha-melanocyte-stimulating hormone. Proc Natl Acad Sci USA 92:8016-8020

Weinstein RS, Chen JR, Powers CC (2002) Inhibition of osteoblastogenesis and promotion of apoptosis of osteoblasts and osteocytes by glucocorticoids. J Clin Invest 109:1041-1048

Weinstein RS, Jia D, Powers CC, Stewart SA, Jilka RL, Parfitt AM, Manolagas SC (2004) The skeletal effects of glucocorticoid excess override those of orchidectomy in mice. Endocrinology 145:1980-1987 